\title{
Herpetic pneumonitis following posterior fossa surgery
}

Denis Ladouceur, MD, Raymond Duperval, MD, André Cantin, MD, Eric H Frost, PhD

\begin{abstract}
D Ladouceur, R DUperval, A Cantin, EH Frost. Herpetic pneumonitis following posterior fossa surgery. Can J Infect Dis 1993;4(2):111-114. Reactivation of Herpes simplex virus (HSV) following manipulation of the trigeminal nerve root.has been reported in a substantial number of immunocompetent patients. Usually it was manifest as an oral mucocutaneous lesion and considered a benign postoperative complication. In the case described here, however, severe respiratory distress due to herpetic pneumonia developed following a pontocerebellar angle surgery complicated by an orolabial herpetic lesion. The delays necessary to confirm HSV diagnosis prior to initiating treatment are discussed, considering the rarity of this complication following neurosurgery.
\end{abstract}

Key Words: Herpes simplex virus, Pneumonitis, Posterior fossa surgery

\section{Pneumonie herpetique secondaire à une chirurgie de la fosse postérieure}

RÉSUMÉ: La réactivation du virus Herpes simplex (HSV), suite à une chirurgie au voisinage du nerf trijumeau, est une entité bien connue. Cette complication postopératoire se manifeste habituellement par une lésion péri-orale et présente généralement une évolution bénigne. Nous rapportons le cas d'une patiente ayant développé une pneumonie herpétique suite à une chirurgie de l'angle ponto-cérébelleux compliquée d'une lésion péri-orale herpétique. Le délai à poser le diagnostic et instaurer le traitement approprié est discuté en fonction de la rareté de cette complication pulmonaire survenant à la suite dune chirurgie du système nerveux central.

$\mathrm{H}$ ERPES SIMPLEX VIRUS TYPE 1 (HSV-1) IS A UBIQUITOUS human pathogen usually acquired in infancy that causes either asymptomatic infections or mild skin and mucosal diseases. After primary infection, HSV retreats to the trigeminal ganglion establishing a latent, nonreplicative state from which it may reactivate subsequent to stress associated with fatigue, sunlight or fever. Reactivation of HSV is frequently observed as a benign postoperative complication of microsurgical decompression of the trigeminal sensory nerve root (1-4). HSV-2 may give rise to a similar syndrome, but more commonly is spread by sexual contact, infecting the anus and genitalia, and establishing a latent state in the sacral nerve ganglia.

HSV pneumonitis is an uncommon complication, but may occur as focal pneumonia following infection

Departments of Neurosurgery, Infectious diseases, Pneumology, and Microbiology, University of Sherbrooke, Sherbrooke, Quebec Correspondence and reprints: Dr Denis Ladouceur, Centre hospitalier universitaire de Sherbrooke, 3001 12th Avenue North, Sherbrooke, Québec J1H 5N4. Telephone (819) 563-5555

Received for publication January 30, 1992. Accepted June 2, 1992 


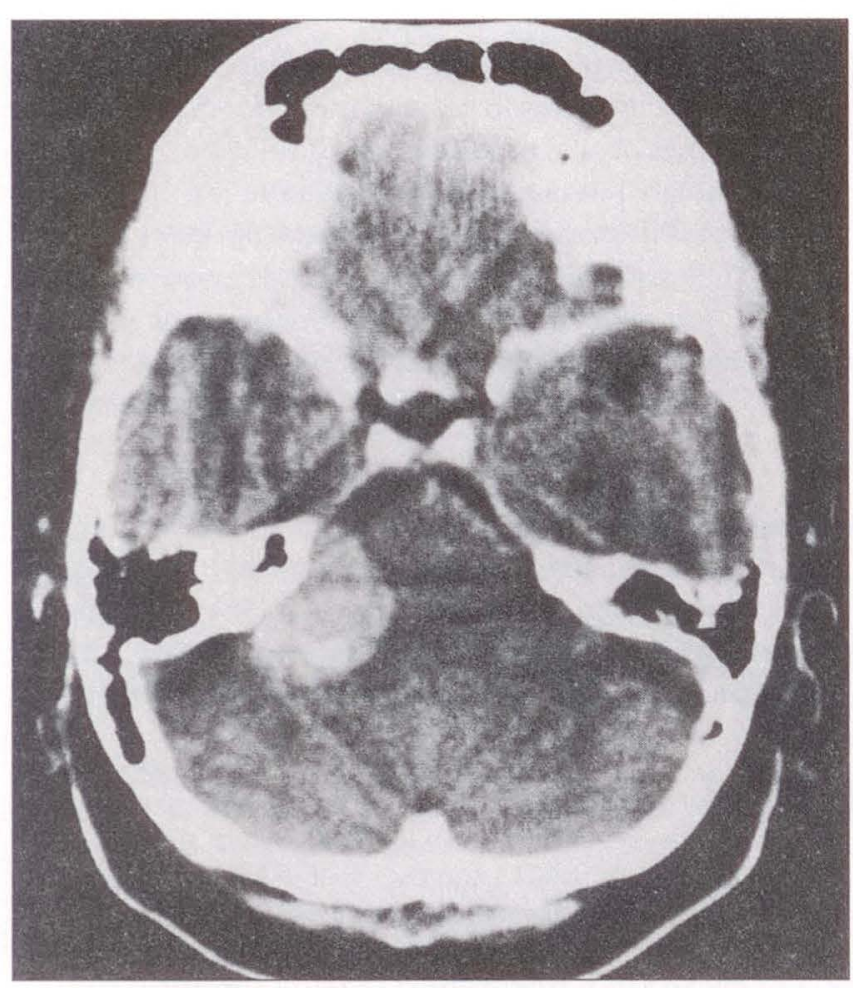

Figure 1) Right acoustic neuroma on axial enhanced computed tomography scan

of the tracheobronchial tree or esophagus and subsequent spread to the lungs, or as diffuse interstitial pneumonia following hematogenous spread from distant sites (5).

This article reports a case of herpetic reactivation following a posterior fossa surgery unusually complicated by herpetic pneumonitis.

\section{CASE PRESENTATION}

A 60-year-old female developed progressively, over the year preceding her admission, an unsteadiness of gait associated with a right-sided deafness and nonpulsatile tinnitus. A few weeks before surgery, she complained of vomiting, nausea and vertigo of increased severity and frequency. A right lower face burning paresthesia was also noted.

Neurological examination disclosed a right neurosensorial deafness and thermoalgesic hypoesthesia of the face, possibly associated with the second branch of the fifth cranial nerve without any abnormalities of the other cranial nerves. Radiological investigations showed a calcified lesion in the right pontocerebellar angle compatible with a right acoustic neuroma $3 \mathrm{~cm}$ in diameter (Figure 1).

Surgery: The patient underwent a right suboccipital craniectomy and total excision of the lesion. Pathological report confirmed a meningioma of the meningotheliomatous histological type.

Postoperative period: Postoperatively, the patient was kept in intensive care for $48 \mathrm{~h}$. She was alert, oriented

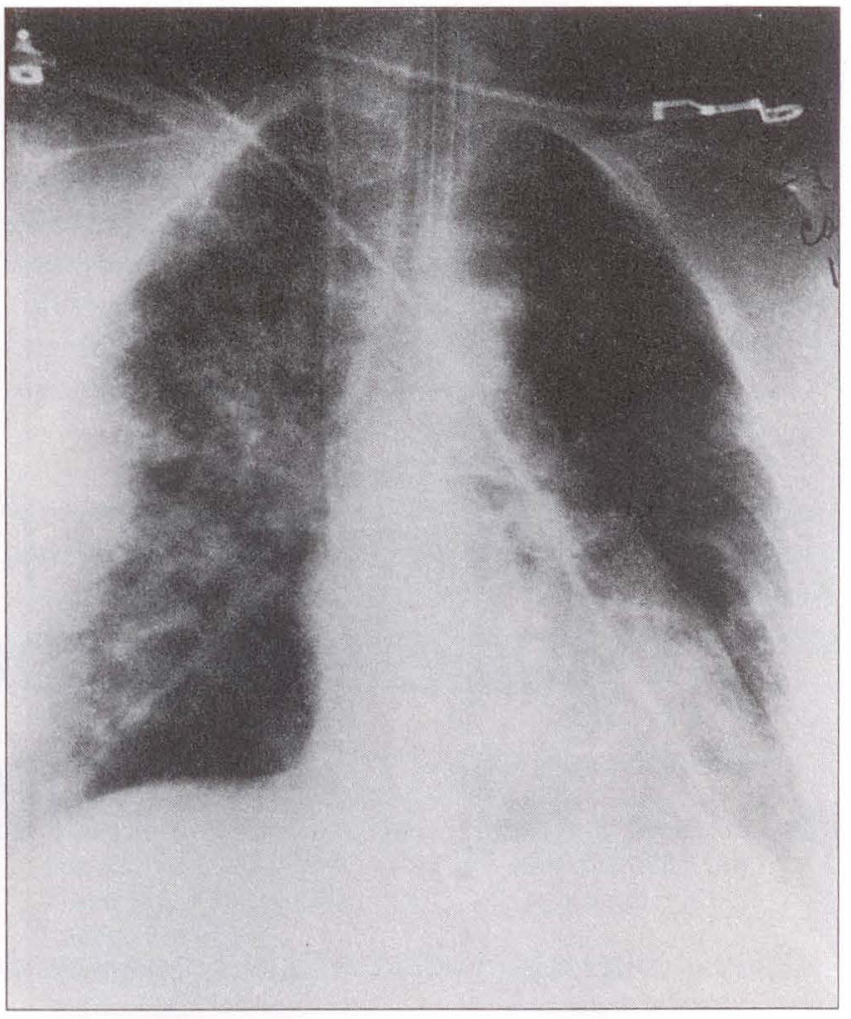

Figure 2) Chest $x$-ray showing diffuse bilateral alveolar infiltrates

in the three spheres. The only deficit was right deafness which was present before surgery. On the second postoperative day, an orolabial lesion (cold sore) developed on the right side of her mouth (ipsilateral to the surgery).

Deterioration of respiratory function started on the fourth postoperative day and she became dyspneic and febrile at $38.8^{\circ} \mathrm{C}$. She was intubated because of progressive hypoxemia at 39 torr with $100 \% \mathrm{~F}_{1} \mathrm{O}_{2}$. Chest $\mathrm{x}$-ray showed diffuse, bilateral alveolar infiltrates (Figure 2). ECG was normal. Culture of bronchial secretions revealed beta-lactamase negative Haemophilus influenzae. She kept deteriorating in spite of initial treatment with gentamicin and cefazoline. Even though alert and conscious, her pulmonary status did not improve enough to allow extubation.

Blood and urine cultures were negative. Computed tomography scan of the brain did not show any evidence of hypertensive intracranial pressure nor abscess formation.

Vesperal febrile peaks up to $40^{\circ} \mathrm{C}$ persisted for five days without significant radiological improvement on serial chest $x$-rays. When bilateral pleural effusion appeared on the fifth antibiotic day, a bronchoscopy was performed showing a small amount of blood-tinged bronchial secretions in the lower lobes on both sides. These specimens were cultured for bacteria (including tuberculosis), fungi and viruses. As the specimen was received in the late afternoon, cultures of African Green Monkey kidney, human diploid fibroblast (MRC-5) and Hep-2 were inoculated the following morning (Friday) 
and at the first control (Monday, day 9) complete cytopathic effect, typical of HSV, was observed in the monkey kidney and MRC- 5 cells but not in Hep-2. A direct examination of the bronchial wash specimen stained by Papanicolaou revealed viral inclusions consistent with herpetic infection. Intravenous acyclovir was started $(10 \mathrm{mg} / \mathrm{kg}$ every $8 \mathrm{~h}$ ) at that time.

A gradual improvement of the patient's condition ensued with defervescence over four days and gradual clearing of the diffuse infiltrate on chest $\mathrm{X}$-ray. She was finally extubated on the 22nd postoperative day. Viral serology for HSV was only requested on days 12 and 23 and revealed titres of $1: 32$ and 1:64, respectively, by complement fixation. Simultaneous serology for varicella zoster virus was negative (less than 1:8) on both days. Acyclovir was stopped after 10 days of treatment.

\section{DISCUSSION}

Although there are numerous causes of pulmonary complications following neurosurgery (6), respiratory distress arising more than $48 \mathrm{~h}$ post surgery, as was observed in the patient presented in this report, is usually indicative of infectious etiology. Postoperative infectious pneumonia may arise in patients with disturbance of their level of consciousness and follows microaspiration of bacteria-contaminated esopharyngeal secretions. Alternatively, hematogenous spread from distant sites (catheters, urine) may occur.

It is not usually assumed that neurosurgery patients are at increased risk for viral pneumonia. On the other hand, reactivation of HSV as orolabial lesions is a very frequent, although benign, complication of trigeminal sensory nerve root surgery, being reported in 35 to $90 \%$ of cases $(3,4,7)$. In one study, throat-wash specimens obtained both pre- and post trigeminal sensory nerve root surgery revealed HSV by culture in 4.5 and $31.6 \%$ (if a history of recurrent herpes labialis is present, it increases to $59.4 \%$ ), respectively, confirming that isolation of HSV was indeed associated with this surgery (7).

Herpetic pneumonia may arise following aspiration of HSV in immunosuppressed or acutely ill patients, especially those with extensive burns, disseminated malignancy or after prolonged endotracheal intubation $(1,2,8,9)$. Patients without serious underlying disease may also develop symptomatic herpetic tracheobronchitis and/or pneumonitis. Most commonly HSV infection of the tracheobronchial tree or esophagus leads to contiguous spread of infection or aspiration into the lungs resulting in focal or multifocal pneumonitis. Other patients, such as the current case, present with diffuse, bilateral interstitial infiltrates. This type of pneumonitis is usually the result of hematogenous spread from distant sites, either genital or oral $(1,5)$. Unless mucosal lesions or tracheobronchitis are clinically obvious, the symptoms and signs of HSV pneumonia are nonspecific.
Laboratory diagnosis of HSV usually depends on culture in human embryonic fibroblasts or primary rabbit kidney cultures where cytopathic effect normally appears within $48 \mathrm{~h}$ of infection. Direct antigen detection in the specimen or after enhancement by centrifugation and culture in a shell vial may slightly reduce the time required for positive identification of HSV at the expense of a slight reduction in sensitivity $(10,11)$, but in most laboratories the obligation to batch samples in order to reduce the number of controls negates any advantage these procedures may have in rapidity. In theory, confirmation of positive cytopathic effect for HSV in culture by immunofluorescent staining with monoclonal antibodies lends credence to the laboratory report whereas, in practice, few cultures judged positive for HSV by cytopathic effect in culture cannot be confirmed. Indeed, of 548 cultures considered positive for cytopathic effect in our laboratory, only three were not confirmed by immunofluorescence (unpublished data).

Retrospective identification by serology of HSV as an etiological agent is usually possible in primary or deepseated infections (such as pneumonia) by complement fixation or the more sensitive enzyme-linked immunosorbent assay or immunofluorescent methodologies, but not in recurrences (1). Because a viral infection was not suspected at onset in the present patient, timing of serum collection was not satisfactory to observe a fourfold diagnostic rise in antibody titre, but only two titres were considered high by complement fixation.

The presence of herpes virus-infected cells in the Papanicolaou-stained cytological specimen, such as was observed in this patient, is generally considered a good indication of the causative role of HSV in pneumonia. Virus present in a latent state or as a result of esopharyngeal contamination of the bronchial washings may result in a positive viral culture, but does not usually show herpes virus-infected cells in a direct cytological examination. Furthermore, the absence of improvement with antibiotics and the clinical and radiological response to acyclovir also indicate a probable HSV pneumonitis in the present patient.

\section{CONCLUSIONS}

The present case demonstrates that even though herpetic pneumonitis is an unusual complication it must be considered even in an immunocompetent patient undergoing a pontocerebellar angle surgery. The clinical presentation of herpetic pneumonia is nonspecific and a mucocutaneous lesion following surgical manipulation in the vicinity of the trigeminal root can be the only clue towards the diagnosis of this unusual postoperative infectious complication. The excellent prognosis following the application of adequate therapy justifies the addition of this entity in the differential diagnosis of pulmonary complications following posterior fossa surgery. 


\section{REFERENCES}

1. Hirsch MS. Herpes simplex virus. In: Mandell GL, Douglas RG Jr, Bennett JE, eds. Principles and Practice of Infectious Diseases, 3rd edn. New York: Churchill Livingstone, 1990:1144-53.

2. Goodman JL. Infections caused by herpes simplex viruses. In: Hoeprich PD, Jordan MC, eds. Infectious Diseases. A Modern Treatise of Infectious Processes, 4th edn. Philadelphia: JB Lippincott Co, 1989:915-30.

3. Janetta PJ. Microsurgical approach to the trigeminal nerve for tic douloureux. Prog Neurol Surg 1976:7:180-200.

4. Pazin GJ, Armstrong JA, Lam MT, Tarr GC, Janetta PJ, Ho M. Prevention of reactivated herpes simplex infection by human leucocyte interferon after operation on the trigeminal root. N Engl J Med 1979;301:225-30.

5. Ramsey PG, Fife KH, Hackman RC, Meyers JD, Corey L. Herpes simplex virus pneumonia: Clinical, virologic and pathologic features in 20 patients. Ann Intern Med 1982;97:813-20.

6. Marshall SB, Marshall LR, Vos HR, Chesnut RM. Neuroscience critical care. In: Eoyang T, ed. Pathophysiology and Patient Management Complications in the Critically Ill Neuro Patient. Philadelphia: WB Saunders Co, 1990:396-405.

7. Pazin GJ, Ho M, Janetta PJ. Reactivation of herpes simplex virus after decompression of the trigeminal nerve root. J Infect Dis 1978;138:405-9.

8. Tuxen DV, Cade JF, McDonald MI, Buchanan MRC, Clark RJ, Pain MCF. Herpes simplex virus from the lower respiratory tract in adult respiratory distress syndrome. Am Rev Resp Dis 1982;126:416-9.

9. Tuxen DV, Wilson JW, Cade JF. Prevention of lower respiratory herpes simplex virus infection with acyclovir in patients with the adult respiratory distress syndrome. Am Rev Resp Dis 1987;136:402-5.

10. Gleaves CA, Wilson DJ, Wold AD, Smith TF. Detection and serotyping of herpes simplex virus in MRC-5 cells by use of centrifugation and monoclonal antibodies $16 \mathrm{~h}$ postinoculation. J Clin Microbiol 1985;21:29-32.

11. Espy MJ, Wold AD, Jespersen DJ, Jones MF, Smith TF, Comparison of shell vials and conventional tubes seeded with rhabdomyosarcoma and MRC- 5 cells for the rapid detection of herpes simplex virus. J Clin Microbiol 1991;29:2701-3. 


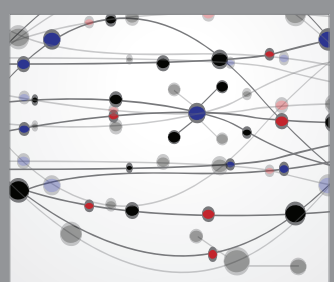

The Scientific World Journal
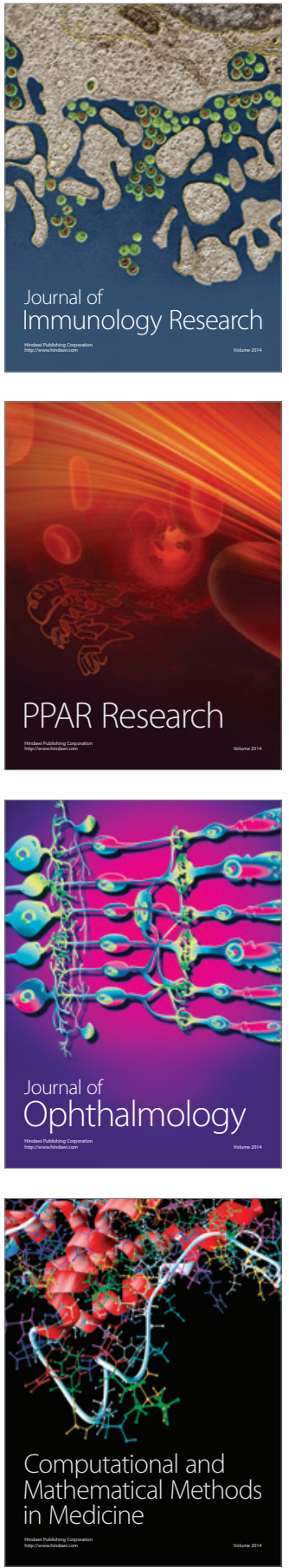

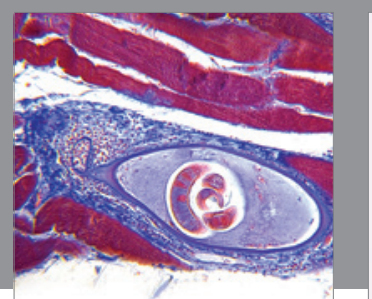

Gastroenterology Research and Practice

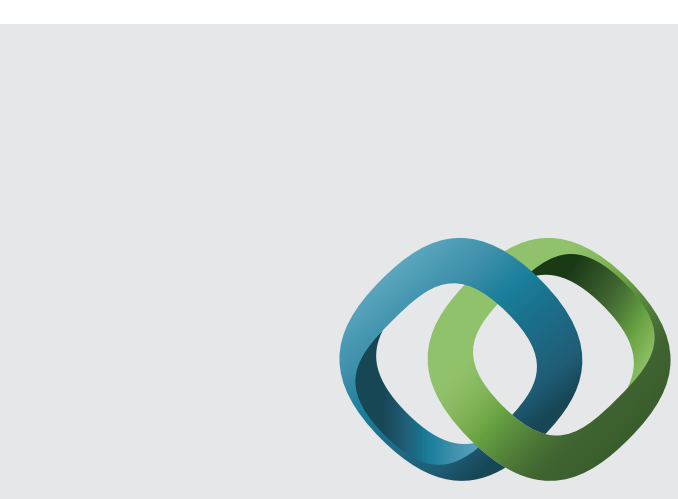

\section{Hindawi}

Submit your manuscripts at

http://www.hindawi.com
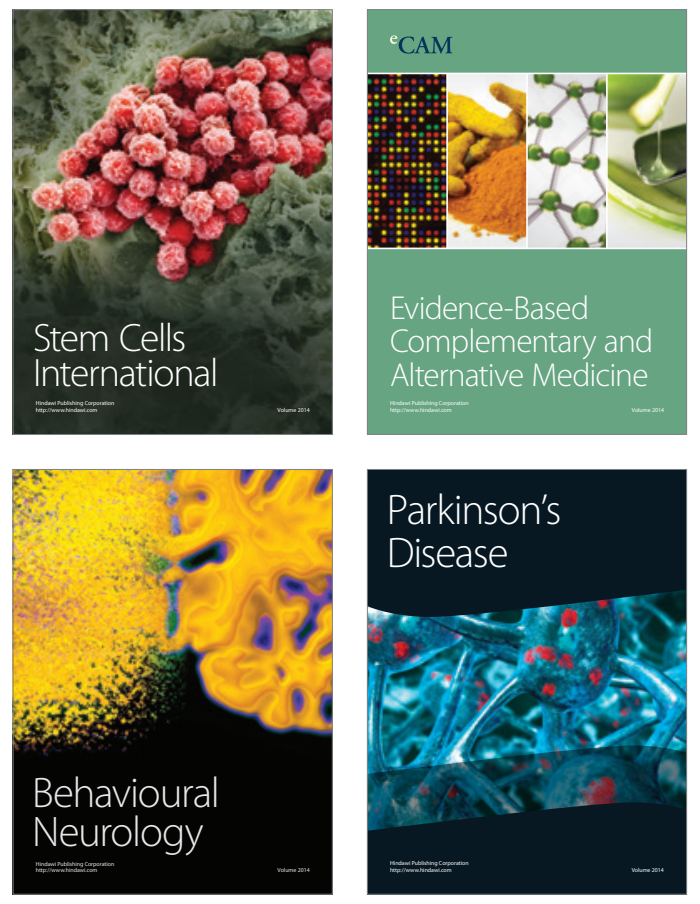
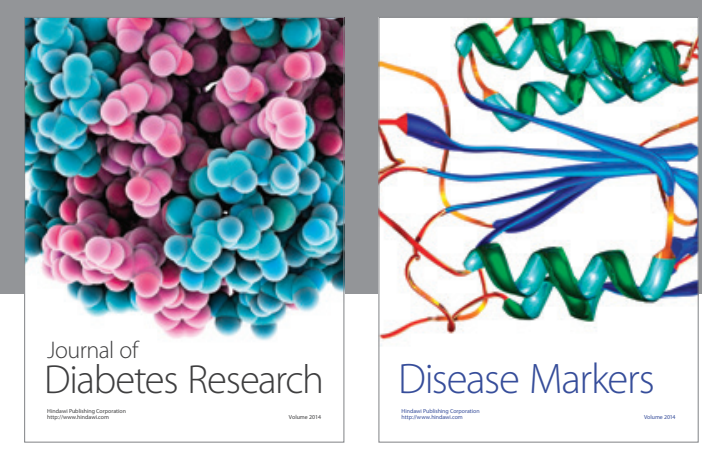

Disease Markers
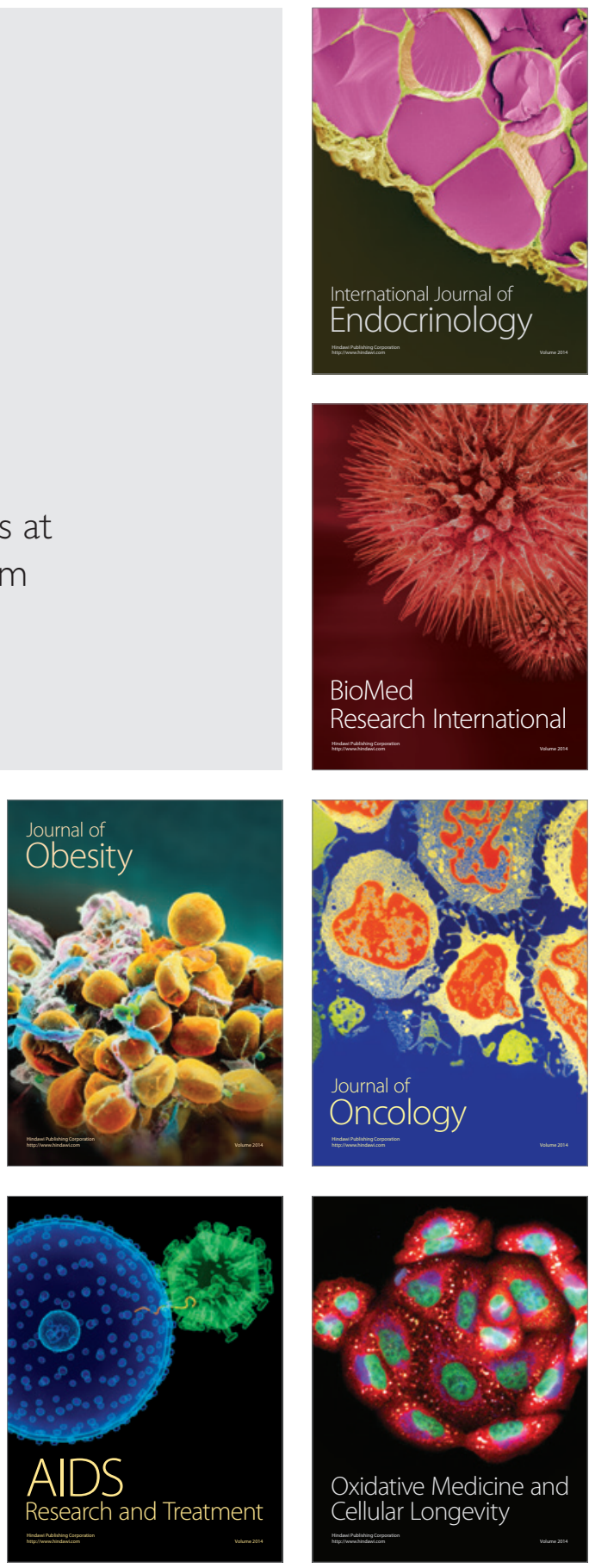